\title{
O futebol brasileiro e a constituição de sujeitos trans: sob as lentes do cronotopo bakhtiniano
}

\author{
Brazilian Football and the Constitution of Trans Subjects: \\ Under the Lens of the Bakhtinian Chronotope
}

\author{
Wilder Kleber Fernandes de Santana \\ Universidade Federal da Paraíba, João Pessoa, Brasil \\ Doutorando em Linguística, UFPB \\ wildersantana92@gmail.com \\ Rafael Marques Garcia \\ Universidade Federal do Rio de Janeiro, Rio de Janeiro, Brasil \\ Doutorando em Educação Física, UFRJ
}

\begin{abstract}
Resumo: 0 presente trabalho delimitou como categoria para subsidiar a pesquisa $o$ cronotopo, termo bakhtiniano que diz respeito a estudos literários e éticos (da cultura humana). Para tanto, fizemos um estudo sobre a constituição de sujeitos trans no futebol contemporâneo brasileiro, em que é preciso recorrer à História, reenunciando dizeres de Platão, Aristóteles dentre outros. O objetivo de nosso trabalho consiste em analisar a constituição de sujeitos trans no futebol contemporâneo brasileiro sob as lentes do cronotopo bakhtiniano, e isso nos impulsionou a traçar processos de (des)naturalização das concepções de sujeito no tempo e no espaço. Em aspectos temáticos, o presente manuscrito aborda o cronotopo e sua implicação para repensar o futebol e os sujeitos trans no futebol contemporâneo brasileiro, situando esse esporte enquanto um importante espaço histórico e simbólico, onde são perceptíveis mudanças nos sujeitos.
\end{abstract}

PalaVRAS-CHAVE: Cronotopo; Sujeitos trans; Futebol contemporâneo.

ABSTRACT: The present paper delimited as a category to subsidize the research the chronotope, bakhtinian term that refers to literary and ethical studies (of the human culture). For that, we made a study about the constitution of trans subjects in the contemporary Brazilian football, in which it is necessary to resort to the History, reenunciating sayings of Plato, Aristotle among others. The objective of our paper is to analyze the constitution of trans subjects in contemporary brazilian football under the lens of the Bakhtinian chronotope, and this has impelled us to trace processes of (dis) naturalization of the conceptions of subject in time and space. In thematic aspects, the present manuscript deals with the chronotope and its implication to rethink football, and trans subjects in contemporary Brazilian football, in which soccer is situated as a historical and symbolic space in which changes in subjects are noticeable.

KEYWORDS: Chronotope; Trans Subjects; Contemporary Football. 


\section{Introdução}

Pesquisar cientificamente sobre a constituição de sujeitos na contemporaneidade não é tarefa fácil, principalmente quando adentramos ao terreno do(s) discurso(s). ${ }^{1}$ Assim, nessa incessante cadência de enunciados que circulam e povoam os atos éticos humanos, traçamos como objetivo analisar a constituição de sujeitos trans no futebol contemporâneo brasileiro sob as lentes do cronotopo bakhtiniano. Nesse sentido, adentramos a uma série de discussões teóricoanalíticas sobre as espacialidades em que o futebol se instaura no Brasil, um território com manifestação ativa da língua portuguesa, em fronteiras com outras esferas comunicativas.

Sob as lentes do cronotopo ${ }^{2}$ considerar o tempo e o espaço como elementos centrais à composição e (re)construção de narrativas, assim como de sujeitos, é imprescindível, uma vez que orientam um processo de conscientização ativa dos seres humanos, não apenas como objetos ou indivíduos, mas como sujeitos axiológicos, dotados de querer e direitos quanto à sua inserção na sociedade. Cabe mencionar que não somos pioneiros na pesquisa sobre o cronotopo bakhtiniano, uma vez que questões relacionadas ao cronos (tempo) e ao topos (espaço), por fazerem parte dos domínio ético, existenciais humanos, estético e cognitivo, ${ }^{3}$ já instigaram muitos pensadores, e estudiosos a traçarem seus pontos de vista sobre este tema: antes de Cristo ganham destaque Platão (428-347 a.C) e Aristóteles (384 a.C.-322 a.C).

No que tange aos estudos sobre os sujeitos trans no futebol contemporâneo brasileiro, nosso arcabouço teórico é formado pelos pesquisadores Bandeira e Seffner (2013), Anjos (2018) e Toledo e Camargo (2018), dentre outros, os quais engendram que o esporte, na contemporaneidade, se consagra como espaço (templo) de reserva masculina, na medida em que constroem corpos sob os moldes

\footnotetext{
${ }^{1}$ SANTANA. Socioalteritarismo: Jesus Cristo e João evangelista em processo de constituição, 2019; SOBRAL. Do dialogismo ao gênero, 2009.

${ }^{2} \mathrm{O}$ cronotopo é um termo que advém do pensamento do filósofo russo Mikhail Bakhtin (18951975), principalmente no que diz respeito aos estudos literários. No entanto, no escopo dos estudos discursivos, enquanto cientistas da linguagem, operamos deslocamentos de sentido e de dimensão analítica, aplicando ao campo da vida humana, conjuntamente a outros estudiosos do pensamento de Bakhtin.

${ }^{3}$ BAKHTIN. Estética da criação verbal, 2006 [1979].
} 
de gênero heterossexuais. A partir dos estudos científicos de Martins e Assunção, ${ }^{4}$ depreendemos que a inserção de sujeitos trans no esporte, especificamente no futebol, é um desafio, pois ainda imperam o preconceito e a discriminação.

Nesse prisma interpretativo, pretendemos, ao delimitar a categoria bakhtiniana cronotopo no âmbito dos estudos éticos contemporâneos, averiguar a participação ativa de sujeitos trans no futebol brasileiro.

Em aspectos estruturais, o presente manuscrito é dividido em seções: "Introdução"; "O cronotopo e sua implicação para repensar o futebol", cujo foco é discutir sobre a importância dos estudos espaço-temporais bakhtinianos para problematizar e fortalecer o futebol como campo inclusivo. "Sujeitos trans no futebol contemporâneo brasileiro: questões político-ideológicas", em que situamos o futebol enquanto espaço histórico e simbólico em que são perceptíveis mudanças nos sujeitos; e "Considerações finais".

\section{O CRONOTOPO E SUAS IMPLICAÇÕES PARA REPENSAR O FUTEBOL}

O cronotopo bakhtiniano consiste na relação entre as noções de tempo e espaço artisticamente assimiladas e perceptíveis no enredo de narrativas, principalmente romances. Ao analisar tal categoria, Bakhtin engendra a linguagem como reflexo e refração da realidade, via estética na literatura. ${ }^{5}$ Volochínov, ao compreender a palavra como uma ponte que liga o eu ao outro, o faz no reconhecimento de que o sujeito se constitui histórica e ideologicamente, em dimensões reais da vivência humana. ${ }^{6}$

É especificamente em um capítulo de Questões de literatura e estética, intitulado "Formas de tempo e cronotopo no romance", que encontramos a produção mais intensa de Bakhtin sobre espacialidades e temporalidades. ${ }^{7}$ Dialogamos, assim, com o manuscrito "Romance de educação na história do realismo", presente em Estética da criação verbal. ${ }^{8}$

\footnotetext{
${ }^{4}$ MARTINS; ASSUNÇÃO. Bichas, macacos, Marias: narrativas de opressão, invisibilidade, preconceito e resistência no futebol, 2019.

${ }^{5}$ BAKHTIN. Estética da criação verbal, 2006 [1979].

${ }^{6}$ VOLOCHÍNOV. Marxismo e filosofia da linguagem, 2017 [1929].

${ }^{7}$ BAKHTIN. Questões de literatura e de estética, 2010 [1930-34].

${ }^{8}$ BAKHTIN. Estética da criação verbal, 2006 [1979].
} 
É preciso situar que, a partir dessa perspectiva sociológica da linguagem, ${ }^{9}$ compreendemos o futebol como uma esfera da atividade humana que se apresenta para além do real, mas também como lugar do simbólico, em que se (des)naturalizam concepções a respeito dos sujeitos que o integralizam.

Etimologicamente, o item lexical cronotopo divide-se em duas raízes gregas: cronos, tempo e topos, espaço/lugar, consistindo na relação indissociável tempo e espaço. Advindo da teoria da relatividade, de Einstein, ${ }^{10}$ que propõe a concepção de tempo e espaço como indissolúveis, o termo cronotopo passa a ser utilizado por Bakhtin em dimensões estética (literária) e ética (histórico-ideológica) do sujeito. É nesse vetor argumentativo que surgem as reflexões de Bemong sobre o pensamento de Bakhtin, para quem os

Avanços de sua época em matemática e física, por sua vez, deram a Bakhtin uma forte convicção de que a natureza das configurações espaçotemporais nos mundos narrativos, embora não totalmente idêntica ao tempo-espaço einsteiniano (o tempo como a quarta dimensão do espaço), compartilha um terreno comum com os princípios da teoria da relatividade. ${ }^{11}$

Na medida em que Bakhtin desenvolveu estudos, em terreno russo, sobre a concepção dialógica da linguagem e do Ser, engendrou "tempo" e "espaço" não como objetos independentes, mas na relação entre eles (relação-relatividade). Essa relação tempo-espaço pode ser percebida, por exemplo, em romances de Dostoievski, cujos os indícios de temporalidades e de espacialidades só fazem sentido dentro do enredo, na vivência plena dos sujeitos que constituem (e são constituídos) (n)o desenrolar dos acontecimentos no tempo. "Os índices do tempo transparecem no espaço, e o espaço reveste-se de sentido e é medido com o tempo".12

Ao percebermos que o pioneirismo de estudos do fator espaço-tempo integraliza narrativas humanas e de personagens literárias, é possível delinear que o cronotopo é atravessado por associação de ideias advindas da mitologia e da

\footnotetext{
${ }^{9}$ VOLOCHÍNOV. Marxismo e filosofia da linguagem, 2017 [1929]; MEDVIÉDEV. O método formal nos estudos literários, 2016 [1928].

${ }^{10}$ EINSTEIN. A teoria da relatividade, 2009.

${ }^{11}$ BEMONG et al. Bakhtin e o cronotopo - reflexões, aplicações, perspectivas, 2015, p. 19.

12 BAKHTIN. Estética da criação verbal, 2006 [1979], p. 233.
} 
religião, segundo Eliade, ${ }^{13}$ da filosofia de Russel $^{14}$ e do estudo de gêneros de romances gregos e no esporte greco-romano. Engendram-se, portanto, na cadência dialogada dos traços espaço-temporais, diferentes axiologias para a compreensão histórica, política e sociológica do sujeito na contemporaneidade.

Para Bakhtin e Medviédev, ${ }^{15}$ os diálogos que se concretizam no tempo, assim como rupturas ideológicas, não se fazem apenas harmonia e concordância, mas sobretudo por tensão, arenas de conflito, controvérsias. Cada período traz consigo seus realces assim como a coloração da dimensão espacial. As representações e os acontecimentos do cotidiano são determinados em um processo de fixação espaço-tempo, permitindo a inscrição de movimentos que deixam suas marcas. Essa fixação "é o resultado de todo trabalho de objetivação",16 e ao mesmo tempo um processo temporário de constituição de sujeitos, que ocupam lugares "determinados" hierarquicamente.

Concordamos, assim, com Garcia e Pereira, para quem "as normas vigentes na esfera esportiva constituem e possibilitam inclusões e exclusões conforme gêneros e performances, sempre através de uma conformidade e lógica heteronormativas". ${ }^{17}$ No entanto, é com o aparecimento de novos aparatos legais que se vislumbra o desabrochar de novos sentidos e significados pela presença de um corpo desviante, ainda que este não se enquadre nos modelos préestabelecidos e que parecem não possuir classificação na prática esportiva. ${ }^{18}$ Ainda na ótica dos pesquisadores, "Esta corporalidade desviada, quando transita entre as polaridades esportivas e se insere no esporte moderno de ordem tradicional, possibilita a amplificação dos horizontes que versam sobre os limites de corpo, sua pluralidade e ambivalência". 19

Eis a maneira de nossa compreensão do Futebol: um espaço heterogêneo de narrativas cuja compreensão efetiva só se dá na narrativa de seu cronotopo, ou

\footnotetext{
${ }^{13}$ ELIADE. História das crenças e das ideias religiosas, volume I: da Idade da Pedra aos mistérios de Elêusis, 2010; ELIADE. O sagrado e o profano, 2013.

${ }^{14}$ RUSSEL. História da filosofia ocidental, 2015.

15 BAKHTIN. Estética da criação verbal, 2006 [1979]; MEDVIÉDEV. O método formal nos estudos literários, 2016 [1928].

${ }^{16}$ AMORIM. Cronotopo e exotopia, 2010, p. 110.

${ }^{17}$ GARCIA; PEREIRA. Ressignificações no esporte através da performance de Tifanny Abreu, 2018, p. 25.

${ }^{18}$ GARCIA; PEREIRA. Ressignificações no esporte através da performance de Tifanny Abreu, 2018.

${ }^{19}$ GARCIA; PEREIRA. Ressignificações no esporte através da performance de Tifanny Abreu, 2018.
} 
seja, na avaliação concreta de sujeitos situados temporal e espacialmente, sem os quais não haveria compreensão. Portanto, para avaliação do futebol brasileiro, em constante diálogo com questões políticas (ideológicas), é necessário averiguar as condições em que se instauram os sujeitos ativos participantes. Delimitamos, como objeto teórico-analítico, sujeitos trans.

Estudos científicos que se pautam pelo cronotopo convocam reflexões sobre as dimensões de ocupações de espaço. Até que ponto alguns sujeitos, em detrimento de outros, podem/são autorizados a ocupar determinados espaços, tendo em vista as configurações discursivo-ideológicas da sociedade? É desse vislumbrar que somos impulsionados ao ato avaliativo: perceber que pessoas/grupos trans têm povoado o futebol em solo brasileiro, uma vez que estes ainda sofrem bastante preconceito tendo em vista o peso ideológico que ainda lhes é marcado pela história tradicional.

Cabe, ainda, mencionar que, ao inserirmo-nos em uma série de discussões cujo direcionamento enunciativo-discursivo seja a prática situada (no tempo e no espaço) de sujeitos ativos, sentimos a responsabilização, enquanto cientistas da linguagem, de ter o cuidado ético e responsivo na mobilização das proposições arguidas e defendidas. Falar sobre futebol enquanto espaço de ações e interpretações é, também, refletir sobre as circunstâncias políticas e ideológicas da época em que ele se configura.

A importância dessas reflexões para o futebol consistem em refletirmos sobre o modo como este se configura a partir da participação ativa de sujeitos trans, na pós-modernidade.

\section{SUJEITOS TRANS NO FUTEBOL CONTEMPORÂNEO BRASILEIRO: QUESTÕES POLÍTICO-IDEOLÓGICAS}

O futebol é uma modalidade esportiva consagrada como templo de reserva masculina, ao mesmo passo que constrói corpos sob os moldes de gênero heterossexuais. ${ }^{20} \mathrm{~A}$ modalidade, não só no Brasil, é um espectro de construção de corpos fortes, aguerridos e determinados, portanto, só absorve as expressões clássicas de homens e suas masculinidades mais viscerais, não à toa inúmeros

${ }^{20}$ BANDEIRA; SEFFNER. Futebol, gênero, masculinidade e homofobia: um jogo dentro do jogo, 2013. 
discursos fóbicos e misóginos irrompem como processos quase que inerentes a este fenômeno moderno. ${ }^{21}$ Nesse sentido,

No que tange ao futebol, pode-se afirmar que entre todas as manifestações de preconceito e discriminação tratadas aqui [racismo, sexismo e misoginia], a homofobia é a mais comum e a menos punida. No Brasil, gritos homofóbicos são considerados como parte do jogo, e a inserção e permanência de pessoas LGBT+ tanto nas arquibancadas quanto nos times profissionais ainda é um tabu. ${ }^{22}$

Os estudos empreendidos por Martins e Assunção revelam a existência dos gritos homofóbicos como integrantes das partidas de futebol, ou seja, a não aceitação do outro por sua condição sexual é externada através de discursos que veiculam e potencializam o grande preconceito que é enraizado em parte da "nobreza" brasileira. É como se houvesse uma necessidade de externar o sentimento de negação subjetiva que há em mim para que eu possa me sobrepor aos meus semelhantes. Entretanto, embora a modalidade ainda permaneça resistente a repaginar seus processos de sociabilidade nos gramados, arenas e círculos identitários, podemos perceber um crescente processo de tensionamento deste cenário através da criação de equipes, campeonatos e torcidas LGBTQI+ ${ }^{23}$

No Brasil, equipes compostas apenas por pessoas trans já é uma realidade desde 2016. A primeira equipe formada apenas por homens trans é da cidade de São Paulo e carrega o nome de Meninos Bons de Bola. ${ }^{24}$ Em 2018, surge o TransViver Futebol Clube, oriundo do Instituto TLGBQI+ Transviver, ${ }^{25}$ de Recife/PE. Em 2019, outros times foram fundados: dois no Rio de Janeiro, o Bigtboys Futebol Clube, ${ }^{26}$ que se denomina como primeiro time de homens trans

\footnotetext{
${ }^{21}$ ANJOS, De "São bichas, mas são nossas" à "Diversidade da alegria": uma história da torcida Coligay, 2018. ANJOS; SILVA JÚNIOR, Recusando armários: histórias de homens homossexuais no futebol brasileiro, 2018. TOLEDO; CAMARGO, Futebol dos futebóis: dissolvendo valências simbólicas de gênero e sexualidade por dentro do futebol, 2018.

${ }^{22}$ MARTINS; ASSUNÇÃO, Bichas, macacos, Marias: narrativas de opressão, invisibilidade, preconceito e resistência no futebol, 2019, p. 354.

${ }^{23}$ PINTO, Torcidas queer e livres em campo: sexualidade e novas práticas discursivas no futebol. 2014. SOUSA; CAMARGO, Coligay e a diversidade sexual no campo esportivo, 2015. ANJOS, De "São bichas, mas são nossas" à "Diversidade da alegria": uma história da torcida Coligay, 2018. ANJOS; SILVA JÚNIOR, Recusando armários: histórias de homens homossexuais no futebol brasileiro, 2018. MARTINS; ASSUNÇÃO, Bichas, macacos, Marias: narrativas de opressão, invisibilidade, preconceito e resistência no futebol, 2019.

${ }_{24}$ Conf.: https://www.instagram.com/meninosbonsdebolafc.

${ }^{25}$ Conf.: https://www.instagram.com/transviver.

${ }^{26}$ Conf.: https://www.instagram.com/bigtboys_fc.
} 
de FUT7 e também o primeiro a ser filiado e federado no Brasil; e Cenus Futebol Clube, ${ }^{27}$ time totalmente voltado, e formado, por rapazes transgênero; novamente em Recife, cria-se o Força Trans Futebol Clube, ${ }^{28}$ voltado para homens trans de Recife e região metropolitana; e mais três em São Paulo, o TransVersão Futebol Clube, ${ }^{29}$ time de futsal pra homens trans que tem por objetivo usar o esporte para unir meninos e meninas em busca do sonho de (r)existir; Os T Mosqueteiros, ${ }^{30}$ para homens trans; e o Camaleões Esporte Clube, que se denomina um núcleo esportivo e cultural LGBTI+ com enfoque nas pessoas trans do projeto Hip Hop Mulher,31 de São Miguel Paulista.

Juntas, essas equipes compõem o quadro nacional de times de futebol composto apenas por pessoas trans, em sua maioria homens, que participam de competições da referida modalidade em território nacional, além de promover uma série de projetos e eventos de conscientização, apoio e acesso à informação por onde transitam.

Embora possam provocar uma desestabilização ao fenômeno esportivo - e em especial, na modalidade futebol -, que insiste em reproduzir os modelos bigenerificados para as categorias de competição, uma análise mais crítica revela que a corporificação dos corpos masculinos trans reforçam os padrões mais viscerais do/no futebol, e também da identificação do gênero à luz da binariedade.

Conforme sugere Preciado, ${ }^{32}$ o fenômeno de desidentificação não é ao todo potencializado, uma vez que os atletas homens trans, embora rompam com a linha da cisgeneridade ${ }^{33}$ e se expressem de forma muitas vezes não inteligível, ainda assim reforçam os qualificadores masculinos. É desse modo que se reafirmam dentro desta categoria e reproduzirem através de seus corpos as características físicas que fixam essa identificação (tais como a barba, o corte de cabelo, os pelos

\footnotetext{
${ }^{27}$ Conf.: https://www.instagram.com/cenusfc.

${ }^{28}$ Conf.: https://www.instagram.com/forcatransfc.

${ }^{29}$ Conf.: https://www.instagram.com/transversaofc.

${ }^{30}$ Conf.: https://www.instagram.com/ostmosqueteiros.

${ }^{31}$ Conf.: https://www.instagram.com/hiphopmulher.

32 PRECIADO. Multidões queer: notas para uma política dos "anormais", 2011.

${ }^{33}$ Simakawa assim define a cisgeneridade: "[...] pode ser resumida como sendo a identidade de gênero daquelas pessoas cuja 'experiência interna e individual do gênero' corresponda ao 'sexo atribuído no nascimento' a elas. Em outras palavras, o termo 'cisgênero' é um conceito que abarca as pessoas que se identificam com o gênero que Ihes foi determinado quando de seu nascimento" (2016, p. 44).
} 
pelo corpo etc.). Dubiamente, promovem rupturas e tensões significativas, já que se inserem em um espaço até então hostil para pessoas que não sejam homens cisgênero, configurando assim o discurso de resistência e ressignificação declamado como missão e objetivo dos clubes em questão. Nos termos do pesquisador, "As identificações negativas [...] são transformadas em possíveis lugares de produção de identidades resistentes à normalização, atentas ao poder totalizante dos apelos à 'universalização'". ${ }^{34}$

A maneira como esses sujeitos (sobre)vivem no espaço do futebol desperta uma reflexão acerca das diferenças entre sexo e gênero, oriundo do contrato social heterocentrado. ${ }^{35}$ Amparado $^{36}$ pela sua teorização da contrassexualidade, isto é, uma proposta de substituição a esse contrato social, o autor defende a ideia de que

os corpos reconhecem não a si mesmos como homens ou mulheres e sim como corpos falantes que reconhecem outros corpos falantes. Reconhecem em si mesmos a possibilidade de aceder a todas as práticas significantes, assim como todas as posições de enunciação, enquanto sujeitos, que a história determinou como masculinas, femininas ou perversas. ${ }^{37}$

Neste sentido, a produção dos corpos trans masculinos no futebol se dá a partir de um sistema heterossexual que atua como um dispositivo social de produção das masculinidades. ${ }^{38} 0$ reflexo dessa produção se dá nos critérios de avaliação desta categoria, onde os jogadores, ao fixarem a identidade de homem trans, parecem-se o mais próximo possível com a figura masculina cisgênera que se quer representar, reafirmando o que seria considerado o "real masculino" e que "toda aproximação imperfeita deve se renaturalizar em benefício do sistema". ${ }^{39}$

Neste direcionamento argumentativo, a produção do corpo masculino trans através dos exercícios físicos - sendo o futebol, neste caso, um dispositivo potencializador deste processo - estaria atrelado a uma série de medidas e adoções estéticas - e até mesmo cirúrgicas - para aproximá-los das características

\footnotetext{
34 PRECIADO. Multidões queer: notas para uma política dos "anormais", 2011, p. 15.

${ }^{35}$ PRECIADO. Manifesto Contrassexual, 2014.

${ }^{36}$ A flexão de gênero se encontra no masculino uma vez que Preciado, embora na época da publicação de seu trabalho ainda se reconhecesse como Beatriz, hoje adotou a identificação de Paul.

${ }^{37}$ PRECIADO. Manifesto Contrassexual, 2014, p. 21.

38 PRECIADO. Manifesto Contrassexual, 2014.

39 PRECIADO. Manifesto Contrassexual, 2014, p. 30.
} 
associadas aos homens cisgênero, tais como força, vigor físico e rigidez muscular. ${ }^{40}$ Através da adoção dessas medidas, o corpo seria repaginado a uma identidade masculina que, com base no contrato social heterocentrado, requer transformações que se distanciem da outrora identidade feminina desses homens trans.

Ainda que Serrano, Caminha e Gomes não tenham se debruçado metodológico-analiticamente sobre a prática de atividades físicas por sujeitos homens trans no futebol, os autores concluem que, para

além dos objetivos físicos/ biológicos na escolha das atividades físicas, existe um processo de "masculinização" - através da produção de uma estética tida como masculina - do corpo, na tentativa de solidificar uma identidade que o transcende. Isto porque, na visão dos homens trans entrevistados, esta nova identidade masculina poderá garantir, além de satisfação com a imagem, pertencimento. ${ }^{41}$

Pensando sobre este prisma, é válido ressaltar que, por vezes, esse processo de fixar uma identificação faz parte de processos sociais e culturais que fogem da alçada de escolha dos próprios sujeitos trans, sejam eles homens ou mulheres. ${ }^{42} 0$ que se pode perceber, em suma, é que, ao mesmo tempo em que rompem com esses padrões, por outro lado os reforçam, ao assumirem para si essa identidade e as qualificações masculinas e/ou femininas, fixando de forma turva o binarismo de gênero.

Tal discussão sugere que, para este momento, a adoção desta postura talvez seja necessária para descentralizar esses saberes hegemônicos concernentes a esses campos cujos quais nos debruçamos a analisar. Concordando com Anjos, não se trata "[...] de recusar a existência ou a possibilidade de pertença ao universo futebolístico de homossexuais afeminados ou transgêneros [mas sim] de problematizar o uso dessa representação como aquela que define [...] de forma necessariamente pejorativa e jocosa". 43

\footnotetext{
40 SERRANO; CAMINHA; GOMES. Homens trans e atividade física: a construção do corpo masculino, 2019.

41 SERRANO; CAMINHA; GOMES. Homens trans e atividade física: a construção do corpo masculino, 2019, p. 7.

${ }^{42}$ Por estarmos tratando de casos específicos em que se fixa uma identidade, trabalhamos essa perspectiva com base nas identificações de homens trans e mulheres trans, não negando, todavia, as inúmeras outras formas de se constituir e entender trans nas sociedades atuais, que escapam ao binarismo de gênero e/ou a modelos possíveis de serem lidos pelo regime heterocentrado.

${ }^{43}$ ANJOS. De "São bichas, mas são nossas" à "Diversidade da alegria": uma história da torcida Coligay, 2018, p.172.
} 


\section{Repensando o futebol}

O movimento trans no esporte, mais especificamente no futebol, embora continue fixando as identidades sexuais e sociais binárias, ainda pode ser lido como extremamente fundamental e necessário. Nesse momento, para poder se inserir e consolidar, talvez seja necessário fixar essa identificação inteligível, já que no futebol, enquanto modalidade pertencente ao universo esportivo, “[...] a exceção é torta, aberrante: lésbicas, gays, bissexuais, pessoas transgênero, orgias sexuais e/com travestis não existem - e na visão de muitos, nunca existirão no rincão masculinista do esporte bretão".44

Para tanto, seria necessário enunciar a materialidade corpórea da identidade masculina trans, recorrendo aos exercícios físicos, ${ }^{45}$ à formação e composição de torcidas LGBTI+ ${ }^{46}$ e à criação de equipes exclusivamente LGBTI+, que participem de torneios e campeonatos. ${ }^{47}$

Uma possível justificativa para isso seria o artifício da passabilidade, importante discurso acionado para preservar a vida precária desses sujeitos trans fora do ambiente competitivo e imerso no cenário social do Brasil que, conste, é o país recordista mundial em crimes de morte e violência cometidos contra sujeitos não heterossexuais, conforme aponta o Relatório 2018 - Mortes violentas de LGBT+ no Brasil, do Grupo Gay da Bahia, primeira e mais importante organização não governamental voltada para a defesa dos direitos humanos de pessoas LGBTI+

\footnotetext{
${ }^{44}$ TOLEDO; CAMARGO. Futebol dos futebóis: dissolvendo valências simbólicas de gênero e sexualidade por dentro do futebol, 2018, p. 103.

45 SERRANO; CAMINHA; GOMES. Homens trans e atividade física: a construção do corpo masculino, 2019.

${ }^{46}$ SOUSA; CAMARGO, Coligay e a diversidade sexual no campo esportivo, 2015. ANJOS. De "São bichas, mas são nossas" à "Diversidade da alegria": uma história da torcida Coligay, 2018. No que concerne à abrangência da sigla, ainda é notório maior engajamento de componentes da letra G (gay) que, embora possa soar como uma desconexão estratificada de toda a classe não heterossexual, indica uma possível porta de ruptura e entrada para as discussões sobre as outras formas de se desenvolver o gosto pela vivência e prática esportiva, especialmente no futebol. Conforme destacam Anjos e Silva Junior (2018, p. 225), "Tanto os BHarbixas quanto outros times gays - Unicorns (SP), Futeboys (SP), BeesCats (RJ), Alligaytors (RJ), Magia (RS), Sereyos (SC), Bravus (DF) - utilizam das redes sociais para divulgar fotos e eventos, postar pequenos vídeos dos encontros e demarcar sua posição de resistência, contrariando a evidente tese de que homossexuais não gostam de futebol".

47 SERRANO; CAMINHA; GOMES, Homens trans e atividade física: a construção do corpo masculino, 2019. MARTINS; ASSUNÇÃO, Bichas, macacos, Marias: narrativas de opressão, invisibilidade, preconceito e resistência no futebol, 2019.
} 
no Brasil. Segundo o relatório, "A cada 20 horas um LGBT morre de forma violenta vítima da LGBTfobia, o que faz do Brasil o campeão mundial de crimes contra as minorias sexuais" (GGB, 2018, p. 1). Ainda, "Em termos relativos, as pessoas trans representam a categoria sexológica mais vulnerável a mortes violentas [...] o risco de uma pessoa trans ser assassinada é 17 vezes maior do que um gay". ${ }^{48}$

À luz de Simakawa, podemos compreender a passabilidade "[...] enquanto uma categoria útil de análise para vivências nas diversidades corporais e de identidades de gênero, tanto como uma exigência cisnormativa, como uma estratégia possível de resistência a cissexismos em determinados contextos". ${ }^{49}$ Assim, a autora reconhece uma dependência à categoria de passabilidade enquanto importante "[...] estratégia de resistência a violências cissexistas", que seria acionado por pessoas trans justamente para poderem (sobre)viver em uma sociedade avessa à este tipo de vida.

Esse processo envolve tanto aspectos visuais/estéticos, tais como a composição corporal, as vestimentas e as expressões às quais se atribuem os gêneros; sonoras, tais como timbre e o tom de voz e o uso de vocabulário específico; e institucionais, tais como a documentação e assistência jurídica, por exemplo. Embora a busca pela passabilidade cis seja uma realidade legítima, é crucial atentarse para que ao mesmo tempo em que pode garantir a resistência de vida de pessoas trans, também desconsidera sua individualidade inerente à condição humana - para aquelas que não almejam essa categorização -, já que a pessoa trans se torna, em alguns casos, retórica refém desse cistema ${ }^{50}$ para sobreviver.

Portanto, ao mesmo tempo em que estabelecemos uma crítica à introjeção dos qualificadores identitários masculinos em homens trans que atuam no/pelo futebol, o

\footnotetext{
${ }^{48}$ GGB. Relatório 2018 - Mortes violentas de LGBT+ no Brasil, p. 2. (Grifos do autor).

${ }^{49}$ SIMAKAWA. Por inflexões decoloniais de corpos e identidades de gênero inconformes: uma análise autoetnográfica da cisgeneridade como normatividade, 2016, p. 158.

${ }^{50}$ Acionamos Simakawa (2016, p. 15) para explicar sobre essa terminologia. A autora, em sua dissertação de mestrado, utiliza o "Cistema-mundo" fazendo referência ao trabalho "Descolonizar as esquerdas ocidentalizadas: para além das esquerdas eurocêntrica rumo a uma esquerda transmoderna descolonial" (2012), do sociólogo porto-riquenho Ramón Grosfoguel, para caracterizá-lo como "[...] "[c]istemamundo ocidentalizado/cristianocêntrico moderno/colonial capitalista/patriarcal" que produz "hierarquias epistêmicas" em que [...] perspectivas não cisgêneras são excluídas, minimizadas, ou silenciadas. A corruptela 'cistema', entre outras corruptelas do tipo, têm o objetivo de enfatizar o caráter estrutural e institucional 'cistêmico' - de perspectivas cis+sexistas, para além do paradigma individualizante do conceito de 'transfobia".
} 
que nos faz questionar até que ponto as rupturas e ressignificações desta modalidade são amplificadas. Entendemos que essa condição seria uma maneira de poder continuar (sobre)vivendo nesta modalidade e também na sociedade brasileira. As dificuldades, conforme apontadas, são inúmeras, e seria injusto exigir deste público que rompessem com essa realidade, uma vez que são inúmeras as formas de ser, estar e se expressar no mundo, que escapam de nossa capacidade de leitura e enquadramento e que, inclusive, nem deveriam ser acionadas desta maneira.

\section{CONSIDERAÇõES FINAIS}

Ao operar deslocamentos semântico-axiológicos em torno do cronotopo, ou seja, estudos e produções discursivas e literárias do tempo-espaço, Bakhtin forneceu ricas contribuiççoes para a crítica literária e para o estudo das tradições históricas, cada época trazendo congigo sua singularidade, as assinaturas de cada era. ${ }^{51}$

A grande importância de termos traçado um perfil teórico-metodológicoanalítico para repensar o futebol a partir de uma perspectiva cronotópica é que, desse modo, estamos vinculados a perspectivas de estudo culturais desenvolvidas no mundo da língua portuguesa. A correlação entre linguagem e esferas ideológicas e políticas se torna imprescindível pela possibilidade de análises mais aprofundadas sobre o corpus estudado. ${ }^{52}$ Estudar linguisticamente é, também, estudar cientificamente, ou seja, incidir olhar(es) sobre o objeto de forma cuidadosa, com experiências concretas de leitura e vivenciamento.

Por fim, esperamos, com este estudo, instigar novas pesquisas que não apenas problematizem instâncias esportivas como o futebol e seu público, mas sobretudo busquem possíveis atos que contribuam para a diluição das problemáticas sociais.

\footnotetext{
${ }^{51}$ SANTANA. Socioalteritarismo: Jesus Cristo e João evangelista em processo de constituição, 2019.

${ }^{52}$ MEDVIÉDEV. O método formal nos estudos literários, 2016 [1928].
} 


\section{REFERÊNCIAS}

AMORIM, Marília de. Cronotopo e exotopia. In: BRAIT, Beth. (Org.). Bakhtin: outros conceitos chave. São Paulo: Contexto, 2010, p. 95-114.

ANJOS, Luiza Aguiar dos. De "São bichas, mas são nossas" à "Diversidade da alegria": uma história da torcida Coligay. Tese (Doutorado em Ciências do Movimento Humano). Universidade Federal do Rio Grande do Sul, Escola de Educação Física, Porto Alegre, 2018.

ANJOS, Luiza Aguiar dos; SILVA JÚNIOR, José Aelson da. Recusando armários: histórias de homens homossexuais no futebol brasileiro. Mosaico, v. 9, n. 14, p. 214231, 2018.

ARISTÓTELES. Física (livros I e II). Trad. Lucas Angioni. São Paulo: Editora da Unicamp, 2009.

BAKHTIN, Mikhail M. Estética da criação verbal. Trad.: Paulo Bezerra, a partir do russo. São Paulo: Martins Fontes, 2006 [1979].

BAKHTIN, Mikhail. Formas de tempo e de cronotopo no romance: ensaios de poética histórica. In: Questões de literatura e estética: a teoria do romance. São Paulo: Editora HUCITEC, 1998, p. 211-362.

BANDEIRA, Gustavo Andrada; SEFFNER, Fernando. Futebol, gênero, masculinidade e homofobia: um jogo dentro do jogo. Espaço Plural, v. XIV, n. 29, p. 246-270, jul.dez. 2013.

BEMONG, Nele et. al. Bakhtin e o cronotopo - reflexões, aplicações, perspectivas. Trad.: Ozíris Borges Filho et. al. São Paulo: Parábola Editorial, 2015.

EINSTEIN, Albert. A teoria da relatividade. Trad.: Silvio Levy. Porto Alegre, L\&PM Editores, 2009.

ELIADE, Mircea. História das crenças e das ideias religiosas, volume I: da idade da Pedra aos mistérios de Elêusis. Trad.: Roberto Cortes de Lacerda. Rio de Janeiro: Zahar, 2010.

ELIADE, Mircea. O sagrado e o profano - a essência das religiões. Trad.: Rogério Fernandes. São Paulo: WMF Martins Fontes, 2013.

GARCIA, Rafael Marques; PEREIRA, Erik Giuseppe Barbosa. Ressignificações no esporte através da performance de Tifanny Abreu. In: E-legis, Brasília, número especial - Pesquisas e Políticas sobre Esporte, nov. 2018.

GGB - Grupo Gay da Bahia. Relatório 2018 - Mortes violentas de LGBT+ no Brasil. Disponível em: https://bit.ly/39WuPyH. Acesso em: 13 dez. 2019.

HOLQUIST, Michael. A fuga do cronotopo. In: BEMONG, Nele et alii. Bakhtin e o cronotopo: reflexões, aplicações, perspectivas. Trad.: Ozíris Borges Filho. São Paulo: Parábola, 2015, p. 34-51.

MARTINS, Débora Nascentes; ASSUNÇÃO, Maria Madalena Silva de. Bichas, macacos, Marias: narrativas de opressão, invisibilidade, preconceito e resistência no futebol. Pretextos - Revista da Graduação em Psicologia da PUC Minas, v. 4, n. 7, p. 342-364, jan.-jun. 2019. 
MEDVIÉDEV, Pável Nikoláievitch. 0 método formal nos estudos literários: introdução a uma poética sociológica. Trad.: Sheila Camargo Grillo e Ekaterina Vólkova Américo. São Paulo: Contexto, 2016.

PINTO, Maurício Rodrigues. Torcidas queer e livres em campo: sexualidade e novas práticas discursivas no futebol. Ponto Urbe - Revista do núcleo de antropologia urbana da USP, n. 14, p. 1-11, 2014.

PLATÃO. Timeu e Crítias - ou "AAtlântida". Trad.: Edson Bini. São Paulo. Edipro, 2012.

PRECIADO, Beatriz (Paul). Manifesto Contrassexual: políticas subversivas de identidade sexual. São Paulo: n-1 edições, 2014.

PRECIADO, Beatriz (Paul). Multidões queer: notas para uma política dos "anormais". Estudos Feministas, v. 19, n. 1, p. 11-20, jan.-abr. 2011.

RUSSELL, Bertrand. História da Filosofia Ocidental. Trad. Hugo Langone. Rio de Janeiro: Nova Fronteira, 2015.

SANTANA, Wilder Kleber Fernandes de. Socioalteritarismo: Jesus Cristo e João Evangelista em processo de constituição. In: Relações linguísticas e axio(dia)lógicas: palavras e escutas exotópicas. São Carlos, Pedro \& João Editores, 2019, p. 4-10.

SERRANO, Jéssica Leite et al. Mulheres trans e atividade física: fabricando o corpo feminino. Interface, v. 23, p. 180624, 2019.

SERRANO, Jéssica Leite; CAMINHA, Iraquitan de Oliveira; GOMES, Isabelle Sena. Homens trans e atividade física: a construção do corpo masculino. Movimento, v. 25, p. 25007, 2019.

SIMAKAWA, Viviane Vergueiro. Por inflexões decoloniais de corpos e identidades de gênero inconformes: uma análise autoetnográfica da cisgeneridade como normatividade. Dissertação (Mestrado em Cultura e Sociedade). Universidade Federal da Bahia, Salvador, 2015.

SOBRAL, Adail. Do dialogismo ao gênero: as bases do pensamento do círculo de Bakhtin. Campinas: Mercado de Letras, 2009.

SOUSA, Vinicius Gomes de; CAMARGO, Wagner Xavier de. Coligay e a diversidade sexual no campo esportivo. Recorde, v. 8, n. 1, p. 1-6, jan.-jun. 2015.

TOLEDO, Luiz Henrique; CAMARGO, Wagner Xavier de. Futebol dos futebóis: dissolvendo valências simbólicas de gênero e sexualidade por dentro do futebol. FuLiA / UFMG, v. 3, n. 3, p. 93-107, set.-dez., 2018.

VOLOCHÍNOV, Valentin Nikholáievich. Marxismo e filosofia da linguagem: problemas fundamentais do método sociológico na ciência da linguagem. Trad.: Sheila Grillo e Ekaterina Vólkova Américo. São Paulo: Editora 34, 2017 [1929].

Recebido para publicação em: 15 dez. 2019.

Aprovado em: 07 jan. 2020. 